\title{
Henry Bauchau en scène
}

\section{Lorena Trione}

\section{(2) OpenEdition \\ Journals}

\section{Édition électronique}

URL : http://journals.openedition.org/studifrancesi/10061

DOI : 10.4000/studifrancesi. 10061

ISSN : 2427-5856

\section{Éditeur}

Rosenberg \& Sellier

\section{Édition imprimée}

Date de publication : 1 août 2017

Pagination : 399-400

ISSN : 0039-2944

\section{Référence électronique}

Lorena Trione, "Henry Bauchau en scène », Studi Francesi [En ligne], 182 (LXI | II) | 2017, mis en ligne le 01 août 2017, consulté le 06 janvier 2021. URL : http://journals.openedition.org/studifrancesi/10061 ; DOI : https://doi.org/10.4000/studifrancesi.10061

Ce document a été généré automatiquement le 6 janvier 2021.

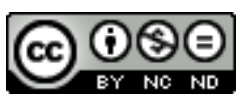

Studi Francesi è distribuita con Licenza Creative Commons Attribuzione - Non commerciale - Non opere derivate 4.0 Internazionale. 


\title{
Henry Bauchau en scène
}

\author{
Lorena Trione
}

\section{RÉFÉRENCE}

Henry Bauchau en scène, «Revue Internationale Henry Bauchau. L'écriture à l'écoute» 7, 2015, 313 pp.

1 Le septième volume de la «Revue internationale Henry Bauchau» se veut une mise au point sur les questions abordées lors du colloque Bauchau en scène qui s'est tenu à Louvain-la-Neuve les 16 et 17 décembre 2013: tout en poursuivant la fouille dans les archives et la bibliothèque de l'écrivain, les chercheurs mettent ici l'accent sur le rôle que le théâtre joua dans l'éclosion de la vocation littéraire de l'auteur. Brouillons à l'appui, l'étude vient ainsi démentir cette idée répandue selon laquelle c'est par la seule poésie que Bauchau s'essaya à l'écriture.

Catherine mayauX et Myriam watTheE-Delmotte (Éditorial, pp. 7-10) introduisent la question du rapport entre Bauchau et le théâtre. La section «Inédits», coordonnée par Pauline BASSO et Jérémy LAMBERT, accueille une transcription de la pièce - demeurant à l'état de brouillon inabouti - de Spartacus ("On ne vit que lorsqu'on aime/On ne vit que si l'on saigne». Le "Spartacus" d'Henry Bauchau, pp. 13-59). Suit un long extrait de la correspondance qu'Henry Bauchau entretint avec le metteur en scène Gisèle SALLIN ( $« e$ que je pense depuis quelque temps, c'est que votre cuvre a du pouvoir», pp. 61-89) au cours des années 1993-1996. C'est à ce moment que germe l'idée d'une collaboration entre les deux auteurs, notamment, pour la réalisation d'une pièce théâtrale à partir du roman ๔dipe sur la route. Le lecteur assiste, au fil des échanges épistolaires, à la transformation d'une entente professionnelle - une «réflexion partagée» (p. 65) - en amitié. En parallèle, on assiste au questionnement de ces deux artistes autour du rôle joué par le théâtre dans la société contemporaine.

3 L'analyse, à ce jour incomplète, du corpus théâtral, y compris les textes adaptés et mis en scène par la suite, fait l'objet du «Dossier thématique» (Jérémy LAMBERT, Myriam WATtheE-DelmotTe, Présentation du dossier, pp. 93-98; Eric Pellet, Le rêve, les bribes et le 
reste. De "La Reine en amont" à "Ceinte", pp. 99-121; Myriam WATTHEE-DELMOTTE, Le théâtre empêché d'Henry Bauchau, pp. 123-139; Jérémy LAMBERT, L'écriture en chantier. Les projets dramaturgiques d'Henry Bauchau (1950-1970), pp. 141-160; Chiara ELEFANTE, La scène "au jour le jour". Le tissage d'un intertexte sur l'écriture théâtrale dans les journaux d'Henry Bauchau, pp. 161-179; Philippe OSMALIN, "CEdipe sur la route" ou le passage à l'acte (théâtral), pp. 181-188; Elsa SIFFERT, Les échos d'Antigone. De la voix au visage, pp. 189-206; Mireille CALLE-GRUBER, De l'écriture pour l'opéra. La voix Bauchau, pp. 207-225; Régis LEFORT, Des cendres au soleil levant, pp. 227-236; Pierre BARTHOLOMÉE, Bauchau en scène et en musique. Roman, livret, opéra: sources, invention, écriture, récritures, pp. 237-244; Catherine MAYAUX, L'archive, devenir et avenir de l'œuvre d'Henry Bauchau?, pp. 245-249; Liste des mises en scène et en voix des cuvres d'Henry Bauchau, pp. 251-261). Si on s'en tenait à l'œuvre publiée (la surface), on aurait tendance à affirmer que Bauchau ne s'essaya au théâtre que sporadiquement. En revanche, le grand nombre de tentatives inabouties (parfois à peine ébauchées, parfois laissées à l'état de brouillons déjà avancés), constitue la preuve tangible que cet auteur ne cessa jamais de tenter la voix-voie, «souterraine» (p. 248) et «empêchée» (p. 97), de la scène. Certains de ces inédits dramatiques sont ici passés en revue et analysés, le but étant de comprendre les raisons qui poussèrent l'écrivain à persister sur cette voie, malgré les difficultés rencontrées dans la «mise en œuvre» (p. 245), les nombreux échecs, la frustration qui en résulte. En particulier, l'accent est mis sur le rythme d'une écriture procédant par visions soudaines, ainsi que sur la quête d'un ton juste et d'un son de voix audible. En ressort une œuvre douée d'une théâtralité intrinsèque, capable de traverser les arts (chant, musique, chorégraphie, vidéo) et les genres (poésie, récit, théâtre, opéra).

Dans la section «Varia», Khalil KHALSI (Sur la route avec l'animal en soi. La destinée selon Henry Bauchau, pp. 265-278) propose une lecture messianique d'une figure récurrente dans l'œuvre bauchalienne, celle de l'animal, «guide» et «instinct» (p. 275) qui conduit les personnages (et leur auteur) vers l'accomplissement de soi et de leur propre destin. Pour sa part, Pierre WIAME (Des "Pierres sauvages" à "La Pierre sans chagrin". Eléments d'un intertexte, pp. 279-288) identifie dans l'importance accordée à l'instinct (dans le processus créateur) un des points de contact entre le recueil La pierre sans chagrin d'Henry Bauchau et le roman - figurant parmi les lectures de l'écrivain - Les pierres sauvages de François Pouillon. L'analyse comparative des deux textes dévoile la présence d'autres éléments d'affinité (mais aussi de divergence), ce qui n'est pas sans rappeler la nécessité d'explorer davantage la bibliothèque de l'auteur, afin d'enrichir la lecture de son œuvre de significations nouvelles et parfois inattendues.

Amateurs et chercheurs sont enfin invités à consulter la section «Actualités» (Jérémy LAMBERT, Actualité scientifique. Bibliographie critique 2013-2014, pp. 291-296; ID., L'année Bauchau 2014, pp. 297-302; ID., Blogs et réseaux sociaux. Henry Bauchau sur la toile, pp. 303-308) pour avoir un aperçu des publications récentes ainsi que des événements qui ont marqué «l'année Bauchau» 2014. 